\title{
Anhedonia difference between major depressive disorder and bipolar disorder II
}

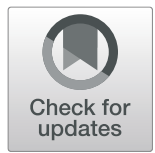

Xinyu Fang ${ }^{1,2+}$, Dandan Wang ${ }^{2 \dagger}$, Wei Tang ${ }^{3}$, Hongyang Liu ${ }^{3}$, Xiangrong Zhang ${ }^{{ }^{*}}$ and Chen Zhang ${ }^{2^{*}}$

\begin{abstract}
Objective: This study aims to explore the difference in anhedonia between Major Depressive Disorder (MDD) and Bipolar Disorder II (BD-II), and attempt to distinguish the two diseases through Snaith-Hamilton Pleasure Scale (SHAPS).

Methods: A total of 164 drug-free depressive patients (98 MDD patients, 66 BD-II patients) completed the investigation. 17-item Hamilton Depression Scale (HAMD-17) and Hamilton Anxiety Scale (HAMA) and SHAPS were assessed in all participants.

Results: Our results showed that BD-II patients had higher SHAPS scores than MDD patients. The stepwise logistic regression analysis further revealed that SHAPS score, drinking habit, and extroversion as influencing factors for the identification of BD-II. The ROC curve analysis indicated that SHAPS could differentiate BD-II from MDD patients ( $A \cup C=0.655, P=0.001,95 \% \mathrm{Cl}=0.568$ to 0.742 ), with the best screening cutoff at 26 , and the corresponding sensitivity and specificity was 0.788 and 0.520 , respectively.

Conclusion: Our results suggest that BD-II patients had more severe anhedonia compared to MDD patients, and the difference in anhedonia may help clinicians preliminary identify BD patients from MDD patients. The preliminary findings are worthly of further exploration.
\end{abstract}

Keywords: Major depressive disorder, Bipolar disorder, Anhedonia Snaith-Hamilton pleasure scale, Drug-free

\section{Introduction}

Major depressive disorder (MDD) and bipolar disorder (BD) are both prevalent and debilitating mood disorders [1], which cause a large burden of disease to the family and society across the world [2,3]. A recent national survey of mental disorders conducted in China demonstrated the lifetime prevalence of MDD and BD is 3.4 and $0.6 \%$ respectively [4]. BD is characterized by recurrent episodes of depression and elevation of mood (mania and/or hypomania). Since the depressive

\footnotetext{
* Correspondence: drxrz@hotmail.com; zhangchen645@gmail.com

${ }^{+}$Xinyu Fang and Dandan Wang contributed to this work equally. They should be regarded as joint first author.

'Department of Geriatric Psychiatry, Affiliated Nanjing Brain Hospital, Nanjing Medical University, Nanjing, People's Republic of China

${ }^{2}$ Shanghai Mental Health Center, Shanghai Jiao Tong University School of Medicine, Shanghai, People's Republic of China

Full list of author information is available at the end of the article
}

symptoms are both common in patients with MDD and $\mathrm{BD}$, and the diagnosis of MDD and BD currently relies on evaluation of symptoms by clinicians [5]. Thus, leads to a high rate of misdiagnosis between these two diseases in clinical practice, especially for BD-II patients, whose hypomanic symptoms in BD have not been recognized, or are yet to appear [6]. A national survey reported that the misdiagnosis rate for $\mathrm{BD}$ reaches as high as $69 \%$, and only $20 \%$ of BD patients with a current depressive episode were correctly diagnosis within the first year of treatment [7]. What's worse, over one-third of $\mathrm{BD}$ patients were still not given a confirmed diagnosis after 10 years of seeking treatment [8]. In clinical practice, the differential diagnosis of depressive episodes of MDD and BD is of great importance, since the drug treatment strategies for relieving depressive symptoms in these two disorders are distinctly different [9]. The

(c) The Author(s). 2021 Open Access This article is licensed under a Creative Commons Attribution 4.0 International License, which permits use, sharing, adaptation, distribution and reproduction in any medium or format, as long as you give appropriate credit to the original author(s) and the source, provide a link to the Creative Commons licence, and indicate if changes were made. The images or other third party material in this article are included in the article's Creative Commons licence, unless indicated otherwise in a credit line to the material. If material is not included in the article's Creative Commons licence and your intended use is not permitted by statutory regulation or exceeds the permitted use, you will need to obtain permission directly from the copyright holder. To view a copy of this licence, visit http://creativecommons.org/licenses/by/4.0/ The Creative Commons Public Domain Dedication waiver (http://creativecommons.org/publicdomain/zero/1.0/) applies to the data made available in this article, unless otherwise stated in a credit line to the data. 
misdiagnosis of BD along with nonideal treatments further results in worsen outcomes, including switching to manic, prolonging illness duration, increasing risk of recurrence and suicide $[6,10]$. Therefore, identification of reliable tools and biomarkers for accurate differential diagnosis of MDD and $\mathrm{BD}$ is of enormous clinical importance.

Up to now, substantial existing research aimed to find biomarkers to discriminate BD from MDD, and some achievement has indeed been made. Since studies of twins and adoptees suggest a genetic predisposition to MDD and $\mathrm{BD}$, some studies found that MDD and $\mathrm{BD}$ had different genetic backgrounds, which provide information for differential diagnosis [11, 12]. Our co-author Chen Zhang has also done a lot of research work on it and revealed some biochemical signatures that could be used for distinguishing BD from MDD, including inflammatory cytokines, brain-derived neurotrophic factor (BDNF), B2RAN2, and ENG proteins [13-15]. In addition, distinct gut microbes, brain structure and functions evaluated by electroencephalogram (EEG) or magnetic resonance imaging (MRI) were all used to classify $\mathrm{BD}$ and MDD patients $[6,9,16]$. However, these findings were poorly repeated by other studies and are still many years away from use in hospitals and clinics.

In clinical practice, it is more urgent to have a convenient tool to assist clinicians in early differential diagnosis of BD and MDD. Hence, some symptoms rating scales were used. The Mood Disorder Questionnaire (MDQ) has been used effectively in the past, which can screen for a lifetime history of manic symptoms in patients with depressive episode [17]. However, the MDQ may be insensitive in the detection of $\mathrm{BD}$ when previous manic or hypomanic symptoms have not been appeared or well recalled. As recent evidence showed a significant difference in somatic symptoms between MDD patients with and without persistent depressive episode [18], other researchers further revealed that MDD patients had more somatic symptoms evaluated by Patients Health questionnaire-15 (PHQ-15) compared to BD-II patients [19]. As we know, anhedonia, a lack of pleasure in response to rewarding stimuli, is a core feature of depression. Ample studies have consistently demonstrated structural and functional aberrance in reward system across patients with BD and MDD [20-22]. These findings suggest that the neural mechanism underlying the anhedonia in BD and MDD might be distinct. However, whether the severity of the anhedonia is different between BD and MDD remains unclear.

In the present study, we used a dedicated tool, the Snaith-Hamilton Pleasure Scale (SHAPS), to evaluate anhedonic symptoms in drug-free patients with MDD and BD-II. We aimed to compare the demographic and clinical differences, including the severity of anhedonia between those two patient groups, and to verify whether SHAPS could assist clinicians to discriminate BD-II from MDD initially.

\section{Materials and methods Participants}

Ninety-eight MDD patients and 66 BD patients in depressive episode were recruited consecutively from Wenzhou Kangning Hospital, Wenzhou Medical University. Each patient was interviewed by two experienced psychiatrists using the Structured Clinical Interview for DSMIV-TR-Patient Edition (SCID-P) and was finally diagnosed with BD or MDD according to DSM-IV. The patients were included only when the diagnosis was consistent between the two psychiatrists. The inclusion criteria are as follows: (1) aged 18-50 years old; (2) total score on the Hamilton Rating Scale for Depression-17 (HAMD-17) $\geq 17$; (3) had a junior high school education or above, understanding and reading fluently in Chinese; (4) did not take any antidepressants during the period of 3 months before enrolment. Exclusion criteria included: (1) comorbid other Axis I psychiatric disorders including those with anxiety disorder, schizophrenia, schizoaffective disorder, or another psychotic disorder; (2) organic brain disease; (3) and those who were pregnant or breastfeeding. All participants provided written informed consent to participate in this study, which was approved by the local Medical Ethics Committee of the Wenzhou Kangning Hospital, and was performed in strict accordance with the Declaration of Helsinki and other relevant national and international regulations.

\section{Date collection}

All participants were interviewed face-to-face. Basic demographic information (age, gender, marital and educational status) and details of the course of the patient's illness, such as age of onset and total disease courses, were obtained by interviewing patients and caregivers, supplemented by their existing medical records. The severity of depressive or anxiety symptoms in all participants was assessed using 17-item Hamilton Depression Scale (HAMD-17) and Hamilton Anxiety Scale (HAMA), the most common tools used by clinician rating of depressive and anxiety symptoms severity. The clinical assessment was conducted by two experienced psychiatrists who were well trained for this project, and repeated assessments for the HAMD-17 or HAMA total score maintained an interrater correlation coefficient greater than 0.8. We used the Snaith-Hamilton Pleasure Scale (SHAPS), Chinese versions, to evaluate the anhedonic symptoms in depressive patients. It is a 14-item self-report questionnaire, which rated on a 4-point Likert scale from definitely agree to definitely disagree. The total score ranges from 14 to 56 for the Chinese 
version of the SHAPS. The higher total SHAPS scores indicate a higher level of anhedonia. It works well in anhedonic assessment and exhibited good reliability and validity with Chinese population [23], and has been widely used to assess anhedonic symptoms in depressed patients in China [24, 25].

\section{Statistical analysis}

Data were analyzed using the Statistical Package for the Social Sciences (SPSS), version 23.0. The statistically significant level was set in alpha $\leq 0.05$ with two-tailed. Clinical and demographic data between MDD and BD-II patients were analyzed by Student's $t$-test for the continuous variables and the chi-squared test for categorical variables. The G*Power 3.1.9.2 program (https://www. softpedia.com/get/Science-CAD/ G-Power.shtml) was used to run a power calculation and determine the effect size of the continuous variables. The stepwise logistic regression analysis was performed to explore influence factors for the identification of BD-II patients. Finally, the receiver operating characteristic (ROC) curve was used to determine whether the patients with $\mathrm{BD}$ and MDD could be differentiated and to ascertain the sensitivity (SEN) and specificity (SPE) at various cutoffs. The best cutoff maximizing the sums of the SEN and SPE were calculated for the SHAPS to discriminate between MDD and BD. The criterion validity of the SHAPS was estimated using the SEN, SPE, false positive rate (FPR), false negative rate (FNR), Youden index and the area under the curve (AUC).

\section{Results}

\section{Demographic and clinical variables in MDD and BD-II} patients

A total of 164 participants were all outpatients, the demographic and clinical characteristics of drug-free patients with MDD and BD-II are presented in Table 1. We found no significant differences between-group differences with regards age, sex, height, weight, education levels, and marital status (All $P>0.05$ ). BD-II patients tend to be more extroverted $\left(\mathrm{X}^{2}=8.283, P=0.016\right)$, and have higher rates for drinking $\left(\mathrm{X}^{2}=6.408, P=0.011\right)$ and smoking ( $\left.X^{2}=6.051, P=0.014\right)$ compared to MDD patients. There were also no significant differences in age of onset, disease courses, and family history of mental illness between BD-II and MDD patients (All $P>0.05$ ). For clinical symptoms, our results showed that BD-II patients had more severe anhedonic symptoms than MDD patients $(\mathrm{t}=3.522, P=0.001)$. However, HAMD-17 and HAMA scores show no significant differences between those two patient groups (Both $\mathrm{P}>0.05$ ). The power calculation showed that the statistical power for the SHAPS reached $96.78 \%$, which indicated a high statistical power of our sample size to detect the difference of SHAPS score between the BD-II and MDD patients. Our stepwise logistic regression analysis further revealed that SHAPS score $\left(\beta=0.108\right.$, Wald $\left.X^{2}=12.031, P=0.001\right)$, drinking habit $\left(\beta=1.214\right.$, Wald $\left.\mathrm{X}^{2}=8.422, P=0.004\right)$ and extroversion $\left(\beta=-0.416\right.$, Wald $X^{2}=5.104, P=$ 0.024 ) as important influencing factors for the identification of BD-II.

\section{ROC curve analysis of SHAPS between MD and BD-II patients}

As shown in Fig. 1, we found SHAPS could differentiate BD-II from MDD patients. The sensitivity, specificity, FPR, FNR, and Youden index are shown in Table S1. According to the Youden index, our results indicated the best screening cutoff between BD-II and MDD was 26 (the value must be an integral number), with the AUC as $0.655(P=0.001,95 \% \mathrm{CI}=0.568$ to 0.742$)$, and the corresponding SEN, SPE, FPR, FNR, and Youden index was $0.788,0.520,0.480,0.212$ and 0.308 , respectively.

\section{Discussion}

Discriminating BD from MDD is a major clinical challenge as misdiagnosis could directly affect the treatment and prognosis of patients. Thus, substantial studies have focused on finding biomarkers for early diagnosis of BD in depressive patients, and progress has indeed been made. However, those findings are far from clinical application. In clinical practice, symptom rating scales play important roles in assisting the diagnosis of diseases. Since evidence supports that MDD and BD patients displayed distinct characteristics of anhedonia, we aimed to compare the demographic and clinical differences between drug-free BD-II and MDD patients, and further to verify whether SHAPS, a tool used to evaluate anhedonia, could be used to help clinicians preliminary identify BD-II patients from MDD patients. The main findings of the present study were as follows: (1) Drug-free BD-II patients had more severe anhedonia, tend to be more extroverted, had a higher rate of drinking and smoking compared to drug-free MDD patients; (2) The stepwise logistic regression analysis revealed that the SHAPS score, drinking habit, and extroversion as influencing factors for the identification of BD-II; (3) SHAPS could differentiate BD-II from MDD patients with the AUC as 0.655 , and the sensitivity was 0.788 at the best screening cutoff 26 .

SHAPS is an excellent tool for assessing anhedonic symptoms in clinical and non-clinical populations [26-28], which is defined as 'markedly diminished interest or pleasure in all, or almost all, activities most of the day, nearly every day [29]. Ample evidence supports that MDD and BD patients had more common and severe anhedonia compared to normal controls [30, 31]. Mazza et al. found that over half of patients diagnosed with $\mathrm{BD}$ experience significant levels of anhedonia 
Table 1 Comparisons between drug-naïve MDD patients and BD-II patients

\begin{tabular}{|c|c|c|c|c|}
\hline & $\operatorname{MDD}(N=98)$ & BD-II $(N=66)$ & $t / X^{2}$ & $P$ \\
\hline Age (year) & $30.37 \pm 7.92$ & $29.94 \pm 8.32$ & 0.333 & 0.740 \\
\hline Sex & & & 1.167 & 0.280 \\
\hline Male & 32 & 27 & & \\
\hline Female & 66 & 39 & & \\
\hline Height (cm) & $167.03 \pm 7.10$ & $166.68 \pm 7.28$ & 0.306 & 0.760 \\
\hline Weight (kg) & $58.46 \pm 10.49$ & $60.41 \pm 14.11$ & 0.958 & 0.340 \\
\hline Character & & & 8.283 & 0.016 \\
\hline Extrovert & 33 & 37 & & \\
\hline Ambivert & 14 & 5 & & \\
\hline Introvert & 51 & 24 & & \\
\hline Marital Status & & & 0.702 & 0.704 \\
\hline Unmarried & 53 & 32 & & \\
\hline Married & 40 & 31 & & \\
\hline Divorced/Widowed & 4 & 2 & & \\
\hline Drinking & & & 6.408 & 0.011 \\
\hline No & 82 & 44 & & \\
\hline Yes & 16 & 22 & & \\
\hline Education (year) & & & 2.842 & 0.092 \\
\hline$\leq 12$ & 36 & 16 & & \\
\hline$>12$ & 62 & 50 & & \\
\hline Smoking & & & 6.051 & 0.014 \\
\hline No & 85 & 47 & & \\
\hline Yes & 13 & 19 & & \\
\hline Age of onset (year) & $29.54 \pm 8.36$ & $28.71 \pm 8.70$ & 0.613 & 0.541 \\
\hline Total disease course (month) & $11.07 \pm 15.70$ & $18.38 \pm 30.62$ & 1.787 & 0.077 \\
\hline Family history & & & 0.338 & 0.561 \\
\hline Yes & 20 & 16 & & \\
\hline No & 78 & 50 & & \\
\hline HAMD-17 & $23.62 \pm 4.48$ & $22.74 \pm 3.58$ & 1.393 & 0.166 \\
\hline HAMA & $19.11 \pm 3.36$ & $18.29 \pm 3.15$ & 1.579 & 0.116 \\
\hline SHAPS & $24.58 \pm 5.54$ & $27.96 \pm 6.66$ & 3.522 & 0.001 \\
\hline
\end{tabular}

Abbreviations: $M D D$ major depressive disorder, $B D$ bipolar disorder, BMI body mass index, HAMD Hamilton Rating Scale for Depression, HAMA Hamilton Rating Scale for Anxiety, SHAPS Snaith-Hamilton Pleasure Scale

Data were presented in Mean \pm SD or $\mathrm{N}$

during a depressive episode [32], and nearly 75\% MDD patients also reported anhedonic symptoms [30, 33]. Those findings highlight the potential of reward processing deficits related to anhedonia to be trait factors of mood disorders. Interestingly, a recent study demonstrated that anhedonia was more frequent in $\mathrm{BD}$ patients compared to MDD patients [34], which is in line with our current findings but opposite to an earlier investigation reported that unipolar depressed patients exhibited greater severity of anhedonia [35]. However, most previous studies did not use specialized tools to assess anhedonia, and this might be the main explanation for the existing discrepancy.
Since anhedonia represents a deficit in reward processing, there have been many studies that reported abnormal reward processing in both MDD and BD patients. In addition, strong evidence indicated different reward processing dysfunction between MDD and BD patients. For instance, Manelis et al. found anticipation of loss was characterized by bottom-up frontostriatal connectivity in MDD, and more sparse connectivity in $\mathrm{BD}$ that lacked fronto-striatal connections [36]. Redlich and colleagues observed that both BD and MDD patients had lower activity in the nucleus accumbens during reward processing, while BD 


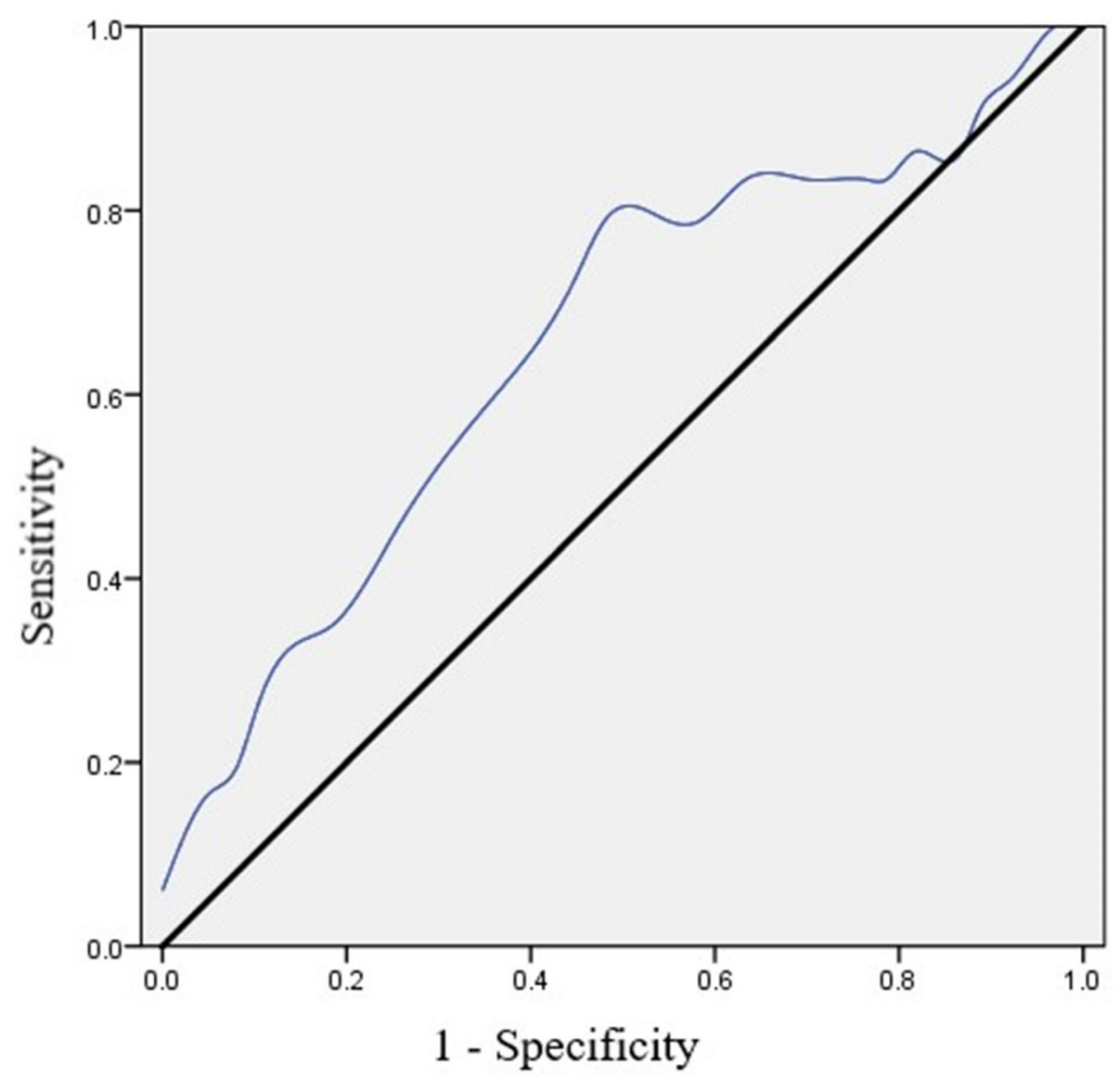

Fig. 1 Receiver operating characteristic (ROC) curve of SHAPS in discriminating BD-II from MDD patients. Note: SHAPS= Snaith-Hamilton Pleasure Scale, $\mathrm{BD}=$ bipolar disorder, $\mathrm{MDD}=$ major depressive disorder

showed a decreased activation, in the reward condition, of the nucleus accumbens, caudate nucleus, thalamus, putamen, insula, and prefrontal areas compared with MDD [37]. Furthermore, immune-inflammatory disturbances have been constantly implicated in the pathophysiology of reward-related disorders [38], and adjuvant anti-inflammatory therapy can significantly improve anhedonia in patients with unipolar and bipolar depression [39]. Interestingly, our previous work found that BD patients and MDD patients showed a distinct characteristic of immune inflammation [13], and immune system-related proteins may be used for distinguishing bipolar depression from MDD [14]. Moreover, as reward processing is modified under conditions of repeated stress, previous studies also suggest that alterations in glucocorticoid mechanism may contribute to anhedonia [40]. Indeed, prior evidence demonstrated the dysregulation of glucocorticoid system in mood disorder [41, 42], but also showed some differences between MDD and BD [43]. Taken together, these foregoing data imply that the anhedonia in MDD and BD may be distinct, and our current study further supported that BD-II at depressive episode had more severe anhedonia compared to MDD patients.

As we know, demographic characteristics did provide clinicians with complementary information for the diagnosis and differential diagnosis of depression to some extent. In the present study, we found that BD-II patients had a higher rate of alcohol use and smoking compared to MDD patients, which was consistent with previous research showed that smoking and alcohol use or dependence are more common in BD patients $[44,45]$. Those results suggest that BD patients may suffer more substance abuse than MDD patients, and this adverse overall relationship between smoking, alcohol use, and $\mathrm{BD}$, regardless of the direction of the effect, deserves major attention from clinicians. In addition, our results also showed that BD patients tend to be more extroverted than MDD patients, which was also reported early [46]. However, other studies failed to detect character differences between these two patient groups [47]. Hence, these relationships should be further explored in the future. 
Some limitations in the present study should be considered. Firstly, owing to the relatively small sample size, especially the BD-II group, the conclusions that can be drawn from our data are limited. Secondly, all participants were recruited from outpatients, thus, our findings might not be generalizable to the inpatients. Thirdly, only a limited number of scales were used in our simple design study, it would be more effective when more symptoms rating scales were combined in identification of BD-II from MDD. Fourthly, the original MDD might be incorrect as the fact of the existence of the misdiagnoses of $\mathrm{BD}$, so the cross-sectional design may lead to bias. Taken together, our preliminary finding should be interpreted with caution due to the above limitations, further study with a larger sample size will be necessary to verify our findings, and longitudinal design is also needed to track the clinical outcomes in patients with MDD.

\section{Conclusion}

The present study provided evidence suggesting anhedonia difference between BD-II and MDD patients, and psychiatrists must pay more attention to anhedonic symptoms in depressive patients.

\section{Supplementary Information}

The online version contains supplementary material available at https://doi. org/10.1186/s12888-021-03548-w.

\section{Additional file 1}

\section{Acknowledgments}

We are deeply grateful to all participants who made contributions to our study for their generous participation, and psychiatrists for their help in the recruitment and diagnosis of patients.

\section{Authors' Contributions}

$X F, X Z$ and $C Z$ conceptualized and designed the study. WT and $\mathrm{HL}$ diagnosed patients, WT and $\mathrm{HL}$ completed the screening assessments. XF and DW analyzed the data and performed the statistical analysis. XF, DW, XZ and $\mathrm{CZ}$ wrote the first draft of the manuscript. All authors revised the manuscript and approved the final manuscript.

\section{Funding}

This work was supported by the National Key Research and Development Program of China (2018YFC1314300 and 2016YFC1307002), the National Natural Science Foundation of China (81771450, 81471358, 81971255 and 81571314), the medical key talent projects in Jiangsu Province (ZDRCA2016075), the Social Development Foundation of Jiangsu Province, China (BE2019610), the Key Project supproted by Medical Science and Technology Development Foundation, Nanjing Department of Health (YKK20090) and the Science and Technology Development Program of Nanjing Medical University (NMUB2019107).

\section{Availability of data and materials}

The datasets used and/or analysed during the current study are available from the corresponding author on reasonable request.

\section{Declarations}

Ethics approval and consent to participate

All participants provided written informed consent to participate in this study, which was approved by the local Medical Ethics Committee of the Wenzhou Kangning Hospital, and was performed in strict accordance with the Declaration of Helsinki and other relevant national and international regulations.

\section{Consent for publication}

Not applicable.

\section{Competing interests}

Authors declare that they have no competing interests.

\section{Author details}

${ }^{1}$ Department of Geriatric Psychiatry, Affiliated Nanjing Brain Hospital, Nanjing Medical University, Nanjing, People's Republic of China. ${ }^{2}$ Shanghai Mental Health Center, Shanghai Jiao Tong University School of Medicine, Shanghai, People's Republic of China. ${ }^{3}$ The Affiliated Kangning Hospital of Wenzhou Medical University, Wenzhou, People's Republic of China.

Received: 19 March 2021 Accepted: 14 October 2021

Published online: 27 October 2021

References

1. Zhang C, Rong H. Genetic advance in depressive disorder. Adv Exp Med Biol. 2019;1180:19-57. https://doi.org/10.1007/978-981-32-9271-0_2.

2. Zhdanava M, Kuvadia H, Joshi K, Daly E, Pilon D, Rossi C, et al. Economic Burden of Treatment-Resistant Depression in Privately Insured U.S. Patients with Physical Conditions. J Manag Care Spec Pharm. 2020;37(1):1-12. https://doi.org/10.1080/03007995.2020.1844645.

3. Walker ER, McGee RE, Druss BG. Mortality in mental disorders and global disease burden implications: a systematic review and metaanalysis. JAMA Psychiatry. 2015;72(4):334-41. https://doi.org/10.1001/jama psychiatry.2014.2502.

4. Huang Y, Wang Y, Wang H, Liu Z, Yu X, Yan J, et al. Prevalence of mental disorders in China: a cross-sectional epidemiological study. Lancet Psychiatry. 2019;6(3):211-24. https://doi.org/10.1016/S2215-0366(18)30511-X.

5. Zheng Y, He S, Zhang T, Lin Z, Shi S, Fang Y, et al. Detection study of bipolar depression through the application of a model-based algorithm in terms of clinical feature and peripheral biomarkers. Front Psychiatry. 2019; 10:266. https://doi.org/10.3389/fpsyt.2019.00266.

6. Rive MM, Redlich R, Schmaal L, Marquand AF, Dannlowski U, Grotegerd D, et al. Distinguishing medication-free subjects with unipolar disorder from subjects with bipolar disorder: state matters. Bipolar Disord. 2016;18(7):61223. https://doi.org/10.1111/bdi.12446.

7. Hirschfeld RM, Lewis L, Vornik LA. Perceptions and impact of bipolar disorder: how far have we really come? Results of the national depressive and manic-depressive association 2000 survey of individuals with bipolar disorder. J Clin Psychiatry. 2003;64(2):161-74. https://doi.org/10.4088/JCP.v64 n0209.

8. Lish JD, Dime-Meenan S, Whybrow PC, Price RA, Hirschfeld RM. The National Depressive and manic-depressive association (DMDA) survey of bipolar members. J Affect Disord. 1994;31(4):281-94. https://doi.org/10.1016/ 0165-0327(94)90104-X.

9. Zheng P, Yang J, Li Y, Wu J, Liang W, Yin B, et al. Gut Microbial Signatures Can Discriminate Unipolar from Bipolar Depression. Adv Sci (Weinheim, Baden-Wurttemberg, Germany). 2020;7(7):1902862.

10. Perlis RH. Misdiagnosis of bipolar disorder. Am J Manag Care. 2005;11(9 Suppl):S271-4

11. Schosser A, Gaysina D, Cohen-Woods S, Chow PC, Martucci L, Craddock N, et al. Association of DISC1 and TSNAX genes and affective disorders in the depression case-control (DeCC) and bipolar affective case-control (BACCS) studies. Mol Psychiatry. 2010;15(8):844-9. https://doi.org/10.1038/mp.2 009.21 .

12. Liebers DT, Pirooznia M, Ganna A, Goes FS. Discriminating bipolar depression from major depressive disorder with polygenic risk scores. Psychol Med. 2020;51(9):1-8. https://doi.org/10.1017/S003329172000015X.

13. Mao R, Zhang C, Chen J, Zhao G, Zhou R, Wang F, et al. Different levels of pro- and anti-inflammatory cytokines in patients with unipolar and bipolar 
depression. J Affect Disord. 2018;237:65-72. https://doi.org/10.1016/j.jad.201 8.04.115.

14. Ren J, Zhao G, Sun X, Liu H, Jiang P, Chen J, et al. Identification of plasma biomarkers for distinguishing bipolar depression from major depressive disorder by iTRAQ-coupled LC-MS/MS and bioinformatics analysis. Psychoneuroendocrinology. 2017;86:17-24. https://doi.org/10.1016/j. psyneuen.2017.09.005.

15. Zhao G, Zhang C, Chen J, Su Y, Zhou R, Wang F, et al. Ratio of mBDNF to proBDNF for differential diagnosis of major depressive disorder and bipolar depression. Mol Neurobiol. 2017;54(7):5573-82. https://doi.org/10.1007/s12 035-016-0098-6.

16. Alamian G, Hincapié AS, Combrisson E, Thiery T, Martel V, Althukov D, et al. Alterations of intrinsic brain connectivity patterns in depression and bipolar disorders: a critical assessment of Magnetoencephalography-based evidence. Front Psychiatry. 2017:8:41. https://doi.org/10.3389/fpsyt.2017. 00041.

17. Yang HC, Liu TB, Rong H, Bi JQ, Ji EN, Peng HJ, et al. Evaluation of mood disorder questionnaire (MDQ) in patients with mood disorders: a multicenter trial across China. PLoS One. 2014;9(4):e91895. https://doi.org/1 0.1371/journal.pone.0091895

18. Hung $\mathrm{Cl}$, Liu CY, Yang CH. Persistent depressive disorder has long-term negative impacts on depression, anxiety, and somatic symptoms at 10-year follow-up among patients with major depressive disorder. J Affect Disord. 2019;243:255-61. https://doi.org/10.1016/j.jad.2018.09.068.

19. Sun DL, Liu QH, Li MJ, Yang Y, Zhang R, Li M, et al. Patient health questionnaire-15 (PHQ-15) to distinguish bipolar II disorder from major depressive disorder. Psychiatry Res. 2020;290:113026. https://doi.org/10.101 6/j.psychres.2020.113026.

20. Alloy LB, Olino T, Freed RD, Nusslock R. Role of reward sensitivity and processing in major depressive and bipolar Spectrum disorders. Behav Ther. 2016;47(5):600-21. https://doi.org/10.1016/j.beth.2016.02.014.

21. Whitton AE, Treadway MT, Pizzagalli DA. Reward processing dysfunction in major depression, bipolar disorder and schizophrenia. Curr Opin Psychiatry. 2015;28(1):7-12. https://doi.org/10.1097/YCO.0000000000000122.

22. Han S, Cui Q, Wang X, Chen Y, Li D, Li L, et al. The anhedonia is differently modulated by structural covariance network of NAc in bipolar disorder and major depressive disorder. Prog Neuro-Psychopharmacol Biol Psychiatry. 2020;99:109865. https://doi.org/10.1016/.jpnpbp.2020.109865.

23. Liu WH, Wang LZ, Zhu YH, Li MH, Chan RC. Clinical utility of the SnaithHamilton-pleasure scale in the Chinese settings. BMC Psychiatry. 2012;12(1): 184. https://doi.org/10.1186/1471-244X-12-184

24. Tang W, Liu H, Chen L, Zhao K, Zhang Y, Zheng K, et al. Inflammatory cytokines, complement factor $\mathrm{H}$ and anhedonia in drug-naïve major depressive disorder. Brain Behav Immun. 2021;95:238-44. https://doi.org/1 0.1016/j.bbi.2021.03.022.

25. Wu C, Lu J, Lu S, Huang M, Xu Y. Increased ratio of mature BDNF to precursor-BDNF in patients with major depressive disorder with severe anhedonia. J Psychiatr Res. 2020;126:92-7. https://doi.org/10.1016/j. jpsychires.2020.05.010.

26. Zhang W, Liao C, Tang F, Liu S, Chen J, Zheng L, et al. Emotional contexts modulate anticipatory late positive component and reward feedback negativity in adolescents with major depressive disorder. Front Psychiatry. 2020;11:358. https://doi.org/10.3389/fpsyt.2020.00358.

27. He Z, Lu F, Sheng W, Han S, Pang Y, Chen Y, et al. Abnormal functional connectivity as neural biological substrate of trait and state characteristics in major depressive disorder. Prog Neuro-Psychopharmacol Biol Psychiatry. 2020:102:109949. https://doi.org/10.1016/j.pnpbp.2020.109949.

28. Yang X, Wang D, Liu S, Liu G, Harrison P. Trajectories of state anhedonia and recent changes in anhedonia in college students: associations with other psychiatric syndromes. J Affect Disord. 2020;262:337-43. https://doi. org/10.1016/j.jad.2019.11.043.

29. Borsini A, Wallis ASJ, Zunszain P, Pariante CM, Kempton MJ. Characterizing anhedonia: A systematic review of neuroimaging across the subtypes of reward processing deficits in depression. Cogn Affect Behav Neurosci. 2020; 20(4):816-41.

30. Cao B, Park C, Subramaniapillai M, Lee $Y$, lacobucci M, Mansur RB, et al. The efficacy of Vortioxetine on Anhedonia in patients with major depressive disorder. Front Psychiatry. 2019;10:17. https://doi.org/10.3389/ fpsyt.2019.00017.

31. Lally N, Nugent AC, Luckenbaugh DA, Ameli R, Roiser JP, Zarate CA. Antianhedonic effect of ketamine and its neural correlates in treatment-resistant bipolar depression. Transl Psychiatry. 2014;4(10):e469. https://doi.org/10.103 8/tp.2014.105.

32. Mazza M, Squillacioti MR, Pecora RD, Janiri L, Bria P. Effect of aripiprazole on self-reported anhedonia in bipolar depressed patients. Psychiatry Res. 2009; 165(1-2):193-6. https://doi.org/10.1016/.jpsychres.2008.05.003.

33. Franken IH, Rassin E, Muris P. The assessment of anhedonia in clinical and non-clinical populations: further validation of the Snaith-Hamilton pleasure scale (SHAPS). J Affect Disord. 2007;99(1-3):83-9. https://doi.org/10.1016/j.ja d.2006.08.020.

34. Gosek P, Heitzman J, Stefanowski B, Antosik-Wójcińska AZ, Parnowski T. Symptomatic differences and symptoms stability in unipolar and bipolar depression. Medical charts review in 99 inpatients. Psychiatr Pol. 2019;53(3): 655-72. https://doi.org/10.12740/PP/102656.

35. Souery D, Zaninotto L, Calati R, Linotte S, Mendlewicz J, Sentissi O, et al. Depression across mood disorders: review and analysis in a clinical sample. Compr Psychiatry. 2012;53(1):24-38. https://doi.org/10.1016/j.comppsych.2 011.01.010.

36. Manelis A, Almeida JR, Stiffler R, Lockovich JC, Aslam HA, Phillips ML. Anticipation-related brain connectivity in bipolar and unipolar depression: a graph theory approach. Brain. 2016;139(Pt 9):2554-66. https://doi.org/10.1 093/brain/aww157.

37. Redlich R, Dohm K, Grotegerd D, Opel N, Zwitserlood P, Heindel W, et al. Reward processing in unipolar and bipolar depression: a functional MRI study. Neuropsychopharmacology. 2015;40(11):2623-31. https://doi.org/10.1 038/npp.2015.110

38. Lee Y, Subramaniapillai M, Brietzke E, Mansur RB, Ho RC, Yim SJ, et al. Anticytokine agents for anhedonia: targeting inflammation and the immune system to treat dimensional disturbances in depression. Ther Adv Psychopharmacol. 2018;8(12):337-48. https://doi.org/10.1177/204512531 8791944.

39. Lee Y, Mansur RB, Brietzke E, Carmona NE, Subramaniapillai M, Pan Z, et al. Efficacy of adjunctive infliximab vs. placebo in the treatment of anhedonia in bipolar I/II depression. Brain Behav Immun. 2020;88:631-9.

40. Lamontagne SJ, Melendez SI, Olmstead MC. Investigating dopamine and glucocorticoid systems as underlying mechanisms of anhedonia. Psychopharmacology. 2018;235(11):3103-13. https://doi.org/10.1007/s00213018-5007-4.

41. Szczepankiewicz A, Leszczyńska-Rodziewicz A, Pawlak J, Rajewska-Rager A, Dmitrzak-Weglarz M, Wilkosc M, et al. Glucocorticoid receptor polymorphism is associated with major depression and predominance of depression in the course of bipolar disorder. J Affect Disord. 2011;134(1-3): 138-44. https://doi.org/10.1016/j.jad.2011.06.020.

42. Abraham A, Watson S, Young AH. Glucocorticoid receptor dysfunction: consequences for the pathophysiology and treatment of mood disorders. Indian J Psychiatry. 2003:45(2):5-14.

43. Szczepankiewicz A, Leszczyńska-Rodziewicz A, Pawlak J, Narozna B, Rajewska-Rager A, Wilkosc M, et al. FKBP5 polymorphism is associated with major depression but not with bipolar disorder. J Affect Disord. 2014;164: 33-7. https://doi.org/10.1016/j.jad.2014.04.002.

44. Angst J, Gamma A, Endrass J, Rössler W, Ajdacic-Gross V, Eich D, et al. Is the association of alcohol use disorders with major depressive disorder a consequence of undiagnosed bipolar-Il disorder? Eur Arch Psychiatry Clin Neurosci. 2006;256(7):452-7. https://doi.org/10.1007/s00406-006-0673-3.

45. Silarova B, Giltay EJ, Van Reedt DA, Van Rossum EF, Hoencamp E, Penninx BW, et al. Metabolic syndrome in patients with bipolar disorder: comparison with major depressive disorder and non-psychiatric controls. J Psychosom Res. 2015;78(4):391-8. https://doi.org/10.1016/j.jpsychores.2015.02.010.

46. Akiskal HS, Kilzieh N, Maser JD, Clayton PJ, Schettler PJ, Traci Shea M, et al. The distinct temperament profiles of bipolar I, bipolar II and unipolar patients. J Affect Disord. 2006;92(1):19-33. https://doi.org/10.1016/j.jad.2 005.12.033.

47. Jylhä $\mathrm{P}$, Mantere $\mathrm{O}$, Melartin $\mathrm{T}$, Suominen $\mathrm{K}$, Vuorilehto $\mathrm{M}$, Arvilommi $\mathrm{P}$, et al. Differences in neuroticism and extraversion between patients with bipolar I or II and general population subjects or major depressive disorder patients. J Affect Disord. 2010;125(1-3):42-52. https://doi.org/10.1016/j.jad.2010.01. 068.

\section{Publisher's Note}

Springer Nature remains neutral with regard to jurisdictional claims in published maps and institutional affiliations. 